\title{
Síndrome de Fahr e Distúrbios do Metabolismo do Cálcio
}

Marise Lazaretti Castro*

Victória Z. Cochenski Borba**

\section{RESUMO}

As calcificações dos núcleos da base, inespecificamente chamadas de síndrome de Fahr, nāo raro são um dos sinais que acabam levando ao diagnóstico de hipoparatireoidismo ou pseudohipoparatireoidismo. Como os pacientes portadores dessas patologias apresentam com freqüéncia outros sinais neurológicos, muitas vezes chegam inicialmente ao neurologista $\theta$ depois de diagnosticados sãn encaminhados ao endocrinologista para tratamento da doença de base. As principais manifestaçōes clinicas da sindrome de Fahr sāo parestesias, tetanias, convulsōes, papiledema (pseudotumor cerebral), catarata, alteraçôes de personatidade e da motricidade. No pseudo-hipoparatireoidismo tipo I, um fenótipo caracteristico lambém pode ser observado, como baixa estatura, fácies arredondada, obesidade troncular, retardo intelectual e encurtamento dos metacarpos. A detecção nos exames laboratoriais de hipocalcemia e hiperfostatemia. na presença de funçāo renal normal, associada a valores inadequados de PTH (reduzidos no hipopara e elevados no pseudo-hipoparatireoidismo) fecham 0 diagnóstico. $O$ tratamento precoce impede a evoluçāo para complicaçōes irreversiveis e controla, em geral, as manifestaçōes neurológicas.

\section{UNITERMOS}

Hipocalcemia, hipoparatireoidismo, sindrome de Fahr, calcificação dos gánglios da base.
- Médica-assistente da Disciplina de Endocrinologia da Escola Paulista de Medicina UNIFESP.

* Pós-graduanda da Disciplina de Endocrinologia da Escola Paulista de Medicina UNIFESP.

\section{INTRODUÇÃO}

A hipocalcemia crônica é causa freqüente de distúrbios neurológicos, podendo se manifestar como parestesias, tetanias, papiledema (pseudotumor cerebral), sinais extrapiramidais, retardo mental, alterações de personalidade, depressão e convulsões. Calcificações dos gânglios da base e cerebelo podem estar presentes no hipoparatireoidismo de longa evolução e caracterizam a síndrome de Fahr descrila em 1930, apesar dessa entidade já ser conhecida por longo tempo antes de sua descrição'.

Faremos uma breve revisão da homeostase do cálcio, causas de hipoparatireoidismo, suas manifestações clínicas e tratamento.

\section{CINÉTICA E HOMEOSTASE DO CÁLCIO}

Uma concentração normal de cálcio no líquido extracelular é fundamental para que muitos processos fisiológicos ocorram e, para isso, o organismo desenvolveu mecanismos cfïcientes. Ao longo do dia, as variações das concentrações plasmáticas de cálcio não ultrapassam $5 \%$. Os valores considerados normais de calccmia total em jejum encontram-se habitualmente entre 8,5 a $10,5 \mathrm{mg} / \mathrm{dL}$. Noventa e nove por cento do cálcio total de um indivíduo está depositado no esqueleto, c o restante encontra-se em forma solúvel nos compartimentos intra e extracelulares. É um ion predominantemente extracelular, e suas concentrações intracelulares chegam a ser até 100.000 vezes menor que fora das células. Pequenas variações de suas concentrações no citoplasma celular são responsáveis por modificações intensas nas funções celulares, funcionando como um segundo mensageiro.

Aproximadamente metade do cálcio circulante está ligada às proteínas plasmáticas, principalmente à albumina, uma pequena parte encontra-se na forma de complexos com ânions, como o citrato e sulfato, $\mathrm{c}$ a outra metade circula na forma de íons livres. É essa porção ionizada do cálcio total que é físiologicamente importante. Em situações clínicas de rotina, a medida do cálcio total freqüentemente é satisfatória. Entretanto, quando as proteínas 
totais potencialmente podem estar alteradas, como em casos de desnutrição, síndrome nefrótica, doenças mieloproliferativas, insuficiência hepática ou renal e outras, recomenda-se a medida do cálcio ionizado. Quando isso não é possível, uma análise das proteínas totais e frações concomitante à dosagem do cálcio total possibilita a obtenção do cálcio corrigido, pela aplicação de uma das várias fórmulas matemáticas disponíveis ${ }^{2.3}$. Somente as alterações nas frações livres do cálcio apresentam repercussão clínica e necessitam, portanto, de tratamento. As variações decorrentes de alterações protéicas não necessitam de qualquer intervenção.

Fórmulas de correção do cálcio total em função das proteínas plasmáticas:

$$
\begin{gathered}
\mathrm{Ca}_{\text {corrigido }}=\mathrm{Ca} \text { total }(\mathrm{mg} / \mathrm{dL})+0,8[4,0 \text {-albumina }(\mathrm{g} / \mathrm{dL})] \\
\text { ou } \\
\mathrm{Ca}_{\text {curigido }}=\mathrm{Ca} \text { total }(\mathrm{mg} / \mathrm{dL}) /[0,6+(\text { Proteína total }(\mathrm{g} / \mathrm{dL}) / 19,4)]
\end{gathered}
$$

A homeostase do cálcio ocorre devido à grande sensibilidade das glândulas paratireóides a pequenas alterações nos níveis séricos de cálcio ionizado. $\mathrm{O}$ hormônio das paratireóides (PTH) é o principal media-

\section{TABELA 1}

\section{Principais causas de hipocalcemias}

- Hipoalbuminemia

- Insuficiência renal crônica

- Deficiência de magnésio

- Hipoparatireoidismo

- Pseudo-hipoparatireoidismo

- Osteomalacia e raquitismo por deficiência ou resistência de vitamina $D$

- Pancreatite aguda

- Rabdomiólise

- Choque séplico

- Doenças malignas

- Síndrome de fome óssea (decorrente da recuperação da doença óssea no hiperparatireoidismo após cirurgia)
TABELA 2

\section{Classificaçāo do hipoparatireoidismo}

I. Falência no desenvolvimento das glândulas paratireóides

11. Desıruição das glândulas paratireóides

A. Cirúrgica

B. Doença poliglandular auto-imune

C. Radiação

D. Depósito de metais (ferro, cobre)

E. Infilltração granulomatosa

F. Invasão neoplásica

III. Alteração funcional das glândulas paratireóides

A. Alteração do receptor/sensor do cálcio

B. Mutação do PTH

C. Hiperparatireoidismo materno

D. Hipomagnesemia

IV. Diminuição da ação do hormônio paratireóide
A. Hipomagnesemia
B. Pseudo-hipoparatireoidismo

dor da homeostase do cálcio por seus efeitos agudos sobre a reabsorção óssea e reabsorção renal de cálcio. Absorção intestinal de cálcio pela produção renal de 1,25-dihidroxivitamina D [1,25 (OH) $\left.\mathrm{D}_{3}\right]$ PTH estimulada requer 24 a 48 horas para tornar-se máxima, portanto só participam da homeostasia quando o estímulo hipocalcêmico é crônico.

A hipocalcemia ocorre quando existe falência ou compensação incompleta dos mecanismos homeostáticos. A hipocalcemia crônica pode ser classificada de acordo com a Tabela 1 . Em geral, os estados hipocalcêmicos podem ser classificados de acordo com os níveis de PTH. Níveis de PTH inadequadamente baixos indicam hipoparatireoidismo. Por outro lado, níveis elevados indicam responsividade normal da glândula paratireóide ao cálcio sérico baixo (hiperparatireoidismo secundário) ${ }^{2,3,4.5}$.

Como o principal enfoque deste artigo é a síndrome de Fahr. ater-nos-emos às patologias que a essa síndrome foram associadas, isto é, ao hipoparatireoidismo e ao pseudo-hipoparatireoidismo (tabela 2). Estados crônicos de hipercalcemia estão sujeitos a calcificações metastáticas (hiperparatireoidismo, síndrome milk-alcali), porém prevalentes em outros tecidos que não o cerebral (rins, músculos, pele, articulações, etc.). 


\section{ETIOLOGLA DOS ESTADOS DE HIPOPARATIREOIDISMO (HP)}

O HP pós-cirúrgico é a causa mais freqüente desle e geralmente é o resultado de tireoidectomia total ou reoperações repetidas para hiperparatireoidismo. A incidência freqüentemente é menor que $5 \%$ e em geral varia entre $1 \%$ a $2 \%$ das cirurgias de paratireóide

Hipoparatireoidismo idiopático caracteriza-se por hipocalcemia com níveis de PTH baixos ou inexistentes. A forma precoce pode ocorrer por falência no desenvolvimento da glândula paratircóide, por agenesia congênita ou hipoplasia que produzem HP no período neonatal. Nesses casos, o HP pode ser isolado (autossômico recessivo ou ligado ao $\mathrm{X}$ ) ou associado a aplasia do timo com imunodeficiência e anomalias cardíacas (síndrome de DiGeorge). HP pode também ocorrer como consequéncia de desordem auto-imune isolada ou em associação com outras deficiências endócrinas. Pode ser esporádico ou familiar, anticorpos antiparatireóides são encontrados em 33\% dos pacientes portadores da forma isolada e em $41 \%$ associada a outras deficiências hormonais ${ }^{2.4}$

Mais raramente, HP ocorre em pacientes submetidos a radioterapia extensa da região cervical e mediastino, em estados de acúmulo de metais pesados como na hemocromatose, talassemia, e doença de Wilson e em infiltração granulomatosa ou neoplásica das paratireóides.

Pode haver ainda alteração da função secretória das paratireóides que pode ser primária ou secundária. Alterações secundárias são aquelas que ocorrem na hipomagnesemia crônica. em fïlhos de mães portadoras de hiperparatircoidismo primário ou em recém-nascidos prematuros. Causas primárias podem ter uma origem genética. há foram descritas diversas mutaçoes presentes no sensor do cálcio, resultando na sua ativação constitutiva. Sua ativação, que fisiologicamente ocorre na presença de quantidades elevadas de cálcio no extracelular. nessas mutações induziriam a supressão da síntese c secreçĩo do PTH, e conseqüentemente a um cstado de hipoparatireoidismo. O receptor de cálcio ativado da glândula suprime cronicamente a secreção de $\mathrm{PTH}^{7}$.

\section{Pseudo-hipoparatireoidismo (PHP)}

As síndromes de resistência ao PTH (PHP) são também causas de hipocalcemia e calcificações cercbrais, porém com níveis de PTH aumentados por irresponsividade dos órgãos-alvo a sua ação biológica.
Dois sào os tipos descritos até os dias de hoje para essa síndrome. dependendo da presença ou não do fenótipo característico e da resposta renal a uma injeção de PTH exógeno. No PHP tipo I, observa-se ausência de resposta renal ao PTH, tanto no que se refere a geração de AMP cíclico. como na indução do efeito fosfatúrico. Observase ainda, nesse tipo, a associação com outras resistências hormonais. como ao TSH, às gonadotrofinas ou ao glucagon, lodos mediados via AMP cíclico. Nesse caso, quando o fenótipo característico (descrito acima) estiver presente, pode ser denominado de osteodistrofia hereditária de Albright. No tipo II, apesar de observarse o incremento esperado no AMP cíclico urinário após infusão endovenosa de PTH exógeno, não ocorre a resposta fosfallúrica e não existe fenótipo característico ${ }^{8}$.

\section{QUADRO CLÍNICO}

A hipocalcemia não é somente a principal consequiencia do hipoparatireoidismo e do pseudo-hipoparatireoidismo. mas também a principal causa de suas manilestaçôes clínicas. Muitas dessas manifestações resultam do aumento da irritabilidade do sistema nervoso perilérico e central. Entretanto, algumas características clínicas podem auxiliar na suspeita do quadro, como a presença de catarata em paciente jovem, pele seca e áspera. cabelo quebradiço, alopecia, dentição alterada. Nos pacientes portadores da osteodistrolia hereditária de Albright, ou pseudo-hipoparatireoidismo tipo I, um fenótipo característico pode ser identificado, como baixa estatura. lácies arredondada, encurtamento de metacarpos ou melatarsos (braquidactilia), ossilicações subcutâncas, rebaixamento intelectual. Entretanto, outras formas de pseudo-hipoparatireoidismo (tipo Ia e tipo II) não apresentam qualquer fenótipo característico.

\section{Tetania}

Existem duas formas de tetania, uma franca e outra latente. A forma franca ocorre em ataques de tetania que se iniciam com sensação de formigamento nas extremidades e nos lábios, evoluindo com piora progressiva da gravidade $\mathrm{e}$ da extensão. atingindo os membros e a face. Segue-se o entorpecimento e espasmo que atingem mais as mãos e os braços que os membros inferiores e, nos casos mais intensos, a face também pode ser atingida.

$\mathrm{Na}$ forma latente, podem ser reconhecidos graus menores de excitabilidade nervosa. Os sinais característicos de tetania latente são os sinais de Chvostek e Trousseau. O sinal de Chvostek é provocado pelo leve 
estímulo do nervo facial aproximadamente $2 \mathrm{~cm}$ na frente do lobo da orelha e abaixo do processo zigomálico. Nos casos positivos ocorre contração dos lábios, asa do nariz, músculo óculo-orbicular e, nos casos mais graves, de todos os músculos inervados pelo facial daquele lado. O sinal de Trousseau ocorre quando o manguito do esfigmomanômetro é inflado na parte superior do braço em nível acima da pressão sistólica. A manilestação sensorial e motora de tetania ocorre na sequiencia em dois minutos, culminando com um ataque típico de espasmo do carpo ${ }^{2.9}$.

Variações na expressão clínica da tetania podem ocorrer principalmente em pacientes crônicos que podem queixar-se somente de parestesias leves, em geral periorais. ou contrações musculares. Pode ocorrer estridor laríngeo pelo espasmo dos músculos da laringe e fixação das cordas vocais na linha média, graus menores de dificuldades na vocalização não são incomuns. Irritabilidade dos gânglios autonômicos está aumentada pela hipocalecmia, com uma variedade de sintomas sendo atribuída ao espasmo da musculatura lisa. Espasmo esofagiano, dor abdominal e pseudoobstrução intestinal são os mais documentados.

A idade é um fator de variação na manifestação clínica de tetania. Crianças pequenas apresentam mais tremores, contrações e convulsões que espasmo carpopedal, provavelmente devido à hipomagnesemia associada. A forma de instalação da hipocalcemia também é um fator importante no aparecimento da tetania. Quando os níveis de cálcio caem rapidamente essa é mais marcida. mesmo com níveis não tão reduzidos de cálcio. Por outro lado, podem estar ate mesmo ausentes nos casos de hipocalcemia de longa duração. Alaques de telania podem ser precipitados ou piorados por hiperventilação, exercício intenso, retirada da medicação tireoideana, infecção, acidose metabólica, uremia e lenitoína. No período pré-menstrual e na gravidez pode ocorrer uma piora dos sintomas pela retenção de sal e água".

\section{Convulsões}

A hipocalcemia aumenta a irritabilidade neuronal central e periférica e convulsões podem ser a manifestação inicial desta, especialmente nos muito jovens ou muito idosos. A hıpocalcemia pode diminuir o limiar excitatório de uma epilepsia preexistente, e as convulsões são indistinguíveis daquelas que ocorrem na presença de cálcio normal e podem ser de qualquer forma. As alterações do eletroencefalograma (EEG) permanecem após a correção da hipocalcemia, apesar da diminuição do número de crises. Devem ser diferenciadas da crise tetânica, que consiste de uma tetania generalizada seguida de espasmos tônicos prolongados. Nesses casos, aura sensorial pode ou não estar presente, porém perda da consciência, ferimento da língua, incontinência esfincteriana e confusão pós-ictal não ocorrem.

A hipocalcemia frequientemente produz mudanças distintas no EEG, estas podem ser vistas em pacientes que têm ou não convulsões. Existe irregularidade e fragmentação na atividade de fundo pós-central, desvio da frequiencia de menos de $4 \mathrm{~Hz}$ para 4 a $8 \mathrm{~Hz}$ e aumento da atividade rápida de baixa frequêencia. Mais característicos são os picos de ondas lentas de alta voltagem que ocorrem com maior frequiência e duração na presença de níveis baixos de cálcio. Se o cálcio cai para niveis inleriores a $6,5 \mathrm{mg} / \mathrm{dL}$, espículas agudas e padrão de ondas podem aparecer. Essas últimas alterações podem desaparecer dentro de poucos dias após a correção da hipocalcemia, porém o padrão de fundo anormal no EEG pode permanecer por semanas".

O sucesso no tratamento da hipocalcemia frequientemente previne ambos os tipos de convulsão e reduz ou cessa a necessidade do uso de anticonvulsivantes.

\section{Calcificações dos gânglios da base e sindrome extrapiramidal}

Na hipocalcemia de longa duração, áreas pequenas, irregulares e discretas de calcificaçōes podem ser vistas 3 a $5 \mathrm{~cm}$ acima da sela túrcica na visão lateral do crânio, e 2 a $4 \mathrm{~cm}$ da linha média na visão frontal. Lesões similares podem ocorrer no núcleo denteado e córtex cerebral. Em todas as localizações as calcificações podem ser detectadas mais precocemente pela tomografia computadorizada que pela radiografia convencional ${ }^{10.11}$

As lesōes consistem de depósitos de sais de cálcio, ferro e outros minerais em um núcleo de material basolílico rico em glicosaminoglicans, que se acumulam dentro c ao redor das paredes dos vasos sangüíneos dos gânglios basais e também no núcleo denteado do cerebclo. Essas calcificações ocorrem em todas as formas de hipoparatireoidismo, quando os pacientes permanecem sem tratamento por tempo suficientemente longo. Nos casos de hipoparatireoidismo pós-cirúrgico, as calcificações são vistas em média 17 anos após a cirurgia".

De 7.040 exames de tomografia computadorizada de crânio. $72(1.02 \%)$ mostraram calcificações intracranianas simétricas. Nos 10 pacientes que apresentavam 
calcificações extensas, hipoparatireoidismo foi facilmente detectado em todos. Em quatro casos, com calcificações menos extensas, as alterações laboratoriais estavam no limite para o diagnóstico de HP. Nos 58 pacientes que apresentavam calcificações limitadas à parte interna do globus pallidus, não foi detectada qualquer relação com distúrbios da função paratireóide ${ }^{12}$.

Calcificações dos gânglios da base podem ocorrer sem alterações neurológicas ou apresentar uma variedade de síndromes extrapiramidais, incluindo Parkinson, coreoatetose e espasmos distônicos. Essas alterações são resistentes ao tratamento-padrão e usualmente melhoram com a restauração da hipocalcemia, a não ser que as calcificações sejam muito extensas.

Calcificações dos gânglios da base ocorrem em uma variedade de outras condições, como a forma familiar de epilepsia associada à hipocalcemia. Nesses casos, acredita-se que alterações da estrutura ou função da membrana têm importância fundamental na gênese da epilepsia familiar e que existe uma determinação genética para o set point do cálcio, explicando a concomitância das duas patologias ${ }^{13}$.

\section{Diagnóstico laboratorial}

As alterações bioquímicas mais importantes são hipocalcemia e hiperfosfatemia na presença de função renal normal. As concentrações séricas de cálcio variam de $6-7 \mathrm{mg} / \mathrm{dL}$ até valores próximos do normal, dependendo da intensidade da doença. $O$ fósforo está em geral elevado, entre 6-7 mg/dL. O PTH imunorreativo está baixo ou indetectável, excelo nos casos de resistência ao PTH, nos quais os níveis estão elevados. O magnésio pode estar diminuído devido à redução da absorção intestinal e da reabsorção tubular de magnésio. A calciúria de 24 horas está diminuída, assim como a excreção do AMP cíclico urinário.

\section{Tratamento}

O objetivo do tratamento em todos os estados de HP é restaurar os níveis de cálcio e fósforo para próximos do normal, que possibilitem o desaparecimento dos sintomas.

O tratamento da crise tetânica é feito pela injeção de cálcio endovenoso com gluconato de cálcio $10 \%$ (possui $90 \mathrm{mg}$ de cálcio/10 mL) ou cloreto de cálcio $10 \%(272$ $\mathrm{mg} \mathrm{de} \mathrm{cálcio/} 10 \mathrm{~mL}$ ), na quantidade necessária para que desapareçam os sintomas, geralmente $200 \mathrm{mg}$ de cálcio. A injeção deve ser feita lentamente (ao longo de 5 minutos), para evitar arritmias cardíacas.
Os principais agentes utilizados para o tratamento da tetania latente e HP crônico são o cálcio e a vitamina $\mathrm{D}$, uma vez que não dispomos do próprio $\mathrm{PTH}$ para esse fim. O cálcio elementar é administrado geralmente na dose de 1-2 g/dia. Uma variedade de preparações de vitamina $D$ pode ser usada, como a vitamina $D_{3}$ ou $D_{2}$ (colecalciferol ou ergocalciferol, respectivamente) nas doses de 25.000-100.000 U (1,25 a $5 \mathrm{mg})$ ao dia. São doses muito elevadas, cerca de 100 a 250 vezes as necessidades fisiológicas diárias desses hormônios. São lipossolúveis e depositam-se no tecido adiposo, e oferecem o risco de intoxicação quando utilizados por longos períodos. $\mathrm{O}$ calcitriol ou $1,25(\mathrm{OH})_{2} \mathrm{D}_{3}$, apesar de mais caro, tem menor risco de intoxicação e é utilizado preferencialmente, na dose de 0,25 a $1 \mathrm{mg}$ ao dia. As doses do cálcio e vitamina D devem ser ajustadas de acordo com o nível sérico de cálcio, que deve ser mantido entre 8 e $8,5 \mathrm{mg} / \mathrm{dL}$ e o cálcio urinário deve-ser mantido em níveis inferiores a $200 \mathrm{mg} / \mathrm{dia}^{2}$.

\section{SUMMARY}

Fahr's syndrome and Calcio Disturbance

Basal ganglia calcifications, inappropriately called Farh's syndrome, usually ends up in the diagnoses of hypoparathyroidism and pseudohypoparathyroidism. Neurological manifestations are frequent. Regularly, these hypocalcemic patients are seen first by the neurologist, and referred to the endocrinologist. Farh's syndrome symptoms inciude paresthesia, tetany, seizures, papilfedema (pseudo-cerebral tumor), cataracts, extrapyramidal signs, molor and personality disturbances. A characteristic phenotype is seen in the pseudohypoparathyroidism " $1 \mathrm{a}$ " and consists of short stature, round facies. mental retardation, obesity and brachydactily. Laboratorial findings of hypocalcemia and hyperphosphatemia in the presence of normal renal function and improper PTH values (low in the hypoparathyroidism and high in the pseudohypoparathyroidism) are the halimarks of the diagnosis. Early treatment prevents evolution to irreversible complications and usually controls neurological manifestations.

\section{KEY WORDS}

Hypocalcemia, hypoparathyroidism, Fahr's syndrome, basal ganglia calcification

\section{Referências}

1. Fahr T. Idiopathische Varkaalkung der himgefasse. Zentralbl Alig Pathol, 50: 129, 1930-1931.

2. Eastell R \& Heath III H. The hypocalcemic states. In: Disorders of bone and mineral metabolism, Coe FL \& Favus MJ (eds). Raven Press, 27: 571-585, 1992.

3. Breslau NA. Calcium, magnesium, and phosphorus: intestinal absorption. In: Favus MJ (ed). Primer on the Metabolic Bone Diseases and Disorders of Mineral Metabolism. Lippincott* Raven Publishers, 7: 220-222, 1996.

4. Aurbach GD, Marx SJ, Spiegel AM. Parathyroid Hormone, Calcitonin, and Calciferois. In: Wilson JD \& Foster DW (eds). Williams textbook of endocrinology. W.B. Saunders Company, 27: 1397-1476, 1996.

5. Shane E. Hypocalcemia: pathogenesis, differential diagnosis, and management. In: Favus MJ (ed). Primer on the Metabolic Bone Diseases and Disorders of Mineral Metabolism. Lippincott-Raven Publishers, 37: 217-219,1996. 
6. Goltzman D, Cole DEC. Hypoparathyroidism. in: Favus MJ (ed). Primer on the Metabolic Bone Diseases and Disorders of Mineral Metabolism. Lippincott-Raven Publishers, 38: 220222, 1996

7. Chattopadhyay N, Mithal A, Brown EM. The calcium-sensing receptor: a window into the physiology and pathophysiology of mineral ion metabolism. Endocr Rev, 17: 4, 289-307, 1996.

8. Levine MA. Parathyroid hormone resistance syndromes. In: Favus MJ (ed). Primer on the Metabolic Bone Diseases and Disorders of Mineral Metabolism. Lippincolt-Raven Publishers, 39: 223-228, 1996

9. Parfitt AM. Surgical, idiopathic, and other varieties of parathyroid hormone-deficient hypoparathyroidism. In: DeGroot LJ (ed). Endocrinology. W.B. Saunders Company, 64: 1049-1064, 1989.

10. Rossi M. Morena M, Zanardi M. Calcification of the basal ganglia and Fahr disease. Report of two clinical cases and review of the literature. Recenti Prog Med, 84: 3, 192-8, 1993.
11. Airias Mayorga $J$, González Martin $T$, Escorial Miguel $C$, Marañon Cabello A. Intracranial calcifications in the differential diagnosis of epileptic disease. Rev Clin Esp, 189: 9, 425-7, 1991.

12. Kazis $A D$. Contribution of $C T$ scan to the diagnosis of Fahr's syndrome. Acta Neurol Scand, 71: 3, 206-11, 1985.

13. Musolino R, De Domenico P, Marino D et al. Epilepsy associated with hypocalcemia: description of a family. Funct Neurol, 7: 3, 215-22, 1992.

Endereço para correspondência:

Rua Botucatu, 740, $2^{9}$ andar - Vila Clementino

Caixa Postal 20266

CEP 04034-970 São Paulo (SP)

E-mail: mcastro@mandic.com.br

OLCADIL -Composição: Comprimidos de 1, 2 e $4 \mathrm{mg}$ de cloxazołam. Indicações: Ansiedade, distúrbios do sono, síndrome de abstinência ao álcool, pré medicação anestésica. Posologia: Dose inicial: pacientes com distúrbios de grau leve ou moderado: 1 a $3 \mathrm{mg}$ ao dia; pacientes com distúrbios de grau moderado ou severo: 2 a $6 \mathrm{mg}$ ao dia. Doses de manutenção: cașos leves de 2 a $6 \mathrm{mg} /$ dia; casos graves de 6 a $12 \mathrm{mg} / \mathrm{dia}$. As doses poderāo ser fracionadas (ver informaçōes completas sobre o produto). Observada melhora, reduzir gradualmente a posologia. Pré-anestesia: 0,1 mg/kg de peso corporal, uma ou duas horas antes da cirurgia, somente nos casos em que é possivel a administração oral. Contra-indicacões: Estados comatosos ou depressão severa do sistema nervoso central; miastenia grave; história de hipersensibilidade a derivados benzodiazepínicos. Precauçōes: Especialmente em doses elevadas, OLCADIL, como todos os medicamentos de ação central, pode comprometer as reaçōes do paciente (ex.: conduçăo de veículos, operaçāo de máquinas, etc.) OLCADIL não é recomendado durante a gravidez e a lactaçāo. Na presença de doença hepática ou renal, sindrome cerebral crônica ou glaucoma de angulo fechado, os pacientes devem ser cuidadosamente monitorizados e, se necessário, a dose de OLCADIL deve ser reduziaa. Embora os benzodiazepínicos apresentem baixo potencial em causar dependéncia $ఠ$ não tenham sido relatados casos de criaçāo de hábito com OLCADIL, deve-se ter cuidado ao prescrever o medicamento a pessoas com tendência a vício. Interaçōes: OLCADIL pode potencializar os efeitos centrais de outros depressores do sistema nervoso central. A ingestão simultânea de álcool não é recomendada. Efeitos colaterais: Sedação, tontura e cefaléia podem ser verificadas com doses elevadas ingeridas de uma só vez. Estes efeitos colaterais geralmente aparecem no inicio do tratamento, mas podem ser evitados pelo aumento gradual da dose, ou podem ser revertidos pela reduçăo da mesma. Hipotensảo ortostástica, hipotonia muscular ou ataxia sāo fenômenos raros. Apresentação: Embalagens com 20 comprimidos de 1, 2 e 4 mg.

Informações completas para prescrição à disposição da classe médica mediante solicitação.

Tegretol $/$ Tegretol• CR - Carbamazepina - Apresentações - Comprimidos: caixas com 20 comprimidos de 200 e 400 mg. Comprimidos de liberaçāo controlada (CR): caixas com 20 comprimidos revestidos divisíveis de 200 e $400 \mathrm{mg}$. Suspensão a $2 \%$ : frasco de $100 \mathrm{ml}$ com copo-medida. Indicaçōes - Epilepsia (exceto crises de ausência). Mania e profilaxia em distúrbios maniacodepressivos (transtornos bipolares). Síndrome de abstinência alcoólica. Neuralgia trigeminal, neuralgia glossofaríngea idiopática. Neuropatia diabética. Diabetes insípidus. Posologia - Adultos: $100-1600 \mathrm{mg} / \mathrm{dia}$, dependendo da indicação e gravidade do caso. Crianças: $10-20 \mathrm{mg} / \mathrm{Kg} / \mathrm{dia}$. Administrado em doses divididas. Contra-Indicaçőes - Hipersensibilidade à carbamazepina ou a compostos tricíclicos. Bloqueio atrioventricular. Uso concomitante de IMAOs. Histórico de depressảo da medula óssea ou de portiria aguda intermitente. Precauções - Gravidez e lactação. Hemograma completo, testes de função hepática e exame de urina no início e periodicamente. Monitorização de níveis plasmáticos. História de insuficiências renal, hepática e cardíaca e de reações adversas hematológicas. Cuidado ao dirigir ou ao operar máquinas. Pressão intraocular aumentada, psicose latente, estados confusionais, agitação. Crises mistas. Pacientes idosos. Interrupçāo abrupta do tratamento. Interaçōes medicamentosas - A carbamazepina é um importante indutor enzimático. Interações clinicamente importantes com outros fármacos / substâncias (inclusive contraceptivos orais e álcool) podem ser comuns. Reaçóes adversas - Efeitos colaterais leves, geralmente transitórios e dose-dependentes. Freqüentes: tontura, ataxia, reaçōes alérgicas cutâneas leves, leucopenia moderada. Ocasionalmente: diplopia, elevação das enzimas hepáticas, vômitos, trombocitopenia, hiponatremia, distúrtios de acomodação. Raros: dermatite exfoliativa, síndrome de StevensJohnson, icterícia, hepatite, distúrbios de hipersensibilidade tardia de vários órgãos, sindrome Lupus-like. Casos isolados: neurites, alucinaçōes, agitação, depressão, síndrome de Lyell, discrasias sangüíneas, reaçōes anafiláticas, bloqueio A-V, insuficiência cardiaca congestiva, tromboembolismo, osteomalacia, disfunção renal, nefrite intersticial, distúrbios sexuais.

Informações completas para prescrição à disposição da classe médica mediante solicitação. 